may inhibit or inactivate selectively a single enzyme. It is probably not unreasonable to assume that disaccharide malabsorption as a cause of disease manifestation, such as chronic diarrhoea and malnutrition, certainly in childhood, is far more common than is suspected.

\title{
REFERENCES
}

Anderson, C. M., Messer, M., Townley, R. R. W. \& Freeman, M. (I963). Pediatrics, 31, I003.

Auricchio, S., Dahlqvist, A., Mürset, G. \& Prader, A. (1963). F. Pediat. 62, 165.

Borgström, B. \& Dahlqvist, A. (1958). Acta chem. scand. 12, 1997.

Careddu, P., Giovannini, M. \& Cevini, G. (1963). Helv. paediat, acta, 18, 97.

Dahlqvist, A. (1962). F. clin. Invest. 4I, 463.

Dahlquist, A. \& Borgström, B. (196I). Biochem. F. 81, 4 I I.

Darling, S., Mortensen, O. \& Søndergaard, G. (1960). Acta paediat., Stockh., 49, 28 I.

Doell, R. G. \& Kretchmer, N. (1962). Biochim. biophys. Acta, 62, 353.

Durand, P. (1958). Minerva pediat. Io, 706.

Fois, A., Vedovini, F. \& Marinello, E. (1960). Acta paediat. lat. 13, 596.

Holzel, A., Mereu, T. \& Thomson, M. L. (1962). Lancet, ii, 1346.

Holzel, A., Schwarz, V. \& Sutcliffe, K. W. (1959). Lancet, i, г 1 26.

Jeune, M., Charrat, A., Cotte, J., Fournier, P. \& Hermier, M. (r960). Pédiatrie, I5, 4 I I.

Lifshitz, F. \& Holman, G. H. (i 964). I. Pediat. 64, 34.

Nordio, S., La Medica, G. \& Vignolo, L. (1961). Minerva pediat. 13, 1766.

Prader, A., Auricchio, S. \& Mürset, G. (196I). Schweiz. med. Wschr. 91, 465.

Von Haemmerli, U. P., Kistler, H. J., Ammann, R., Auricchio, S. \& Prader, A. (I963). Helv. med. acta, 30, 693 .

Weijers, H. A., van de Kamer, J. H., Dicke, W. K. \& Ijsseling, J. (I96r). Acta paediat., Stockh., 5o, 55 .

\section{The systemic influence of carbohydrates on teeth}

\author{
By R. L. Speirs, Department of Physiology, The London Hospital Medical College, \\ London, $E_{\mathbf{I}}$
}

The fact that a symposium, organized by the American Dental Association in 1954, could be entirely devoted to 'the effect of sugars and other carbohydrates on the teeth' clearly indicates the extent of this subject and the necessity of restricting the present discussion to only one aspect. The less well established systemic or nutritional influence of carbohydrates on teeth has been chosen as it seems most in accord with the theme of this meeting. My intention is to assess, from the available experimental evidence, the relative importance of this influence in determining caries susceptibility.

\section{Pre-eruptive influence of carbohydrates}

Sognnaes (1948), in a study which is a landmark in experimental caries research, fed rats and hamsters on a purified, high-sucrose diet before and during the development of the molar teeth of their offspring, that is, during pregnancy and lactation. This resulted in a marked decrease in the caries resistance of these animals compared with others raised from dams on an unrefined stock diet. Less effect was observed when the high-sugar diet was given to the mothers during the lactation period only. Sognnaes \& Shaw (1954) have confirmed these results and have also reported a similar pre-eruptive influence, operating before and after weaning, in the 
teeth of monkeys (Shaw \& Sognnaes, 1955). In several laboratories, however, caries incidence in rats has been almost unaffected by the nature of the prenatal diet (McClure, I95 I ; Haldi \& Wynn, 1952; Watson \& Muhler, I959; Shaw \& Griffiths, 1963). Strain differences and subtle dietary variations are two of several factors suggested by Shaw \& Griffiths ( 1963 ) as being probably responsible for the disagreement between investigators. That caries susceptibility can be influenced by the composition of the maternal diet during lactation has been confirmed in rats (McClure, I95I), and cotton-rats (Shaw, Schweigert, McIntire, Elvehjem \& Phillips, 1944). However, young rats, although still suckling, may have access to the maternal cariogenic diets from about the $\mathrm{I}^{\text {th }}$ day until weaning occurs, or is induced, at $2 \mathrm{I}-25$ days of age. This means that the first and second molars, which calcify during the first $\mathrm{I}_{4}$ days of life and erupt about the 19 th and 2 ist days respectively, would be immediately exposed to these diets. Since newly erupted teeth are regarded as being particularly susceptible to cariogenic diets, this possible influence must be considered in explaining increased caries in animals fed on cariogenic diets from birth rather than from weaning. McClure (I95I) attributed the entire 'lactation effect' to this cause, but recent studies by Steinman and Haley, which will be discussed later, suggest that access to a high-sugar diet before weaning can affect the molars before their eruption. These two suggestions should be regarded as additive rather than as alternative explanations.

The mechanism proposed by Sognnaes (1948) to account for the influence of purified, high-carbohydrate diets on the development of the teeth and their subsequent caries susceptibility was the replacement of some essential element responsible for caries resistance, that was present in the crude stock ration, by the refined dietary components. Carbohydrate per se was not regarded as the critical factor. Such a hypothesis was compatible with the finding that the severity of caries in the offspring was related to the length of time during which the dams consumed the refined diet. It was only partly supported by direct experimental study (Sognnaes \& Shaw, I954) and seemed inadequate to explain the pre-eruptive influence on caries of less purified, high-carbohydrate diets (Ockerse, 1949; Mitchell \& Shafer, I949; McClure, I95 I).

That carbohydrates themselves are potentially cariogenic is suggested as an alternative mechanism by Steinman's work. 'The supplementation of the normal milk diet of suckling rats by carbohydrate solutions given orally throughout the suckling period was associated with higher caries scores than in litter-mates given only water (Steinman \& Haley, 1957a). The possibility that milk consumption might be reduced by the sugar feeds and that this might be responsible for the observed effects was not tested, but the similarity in the weights of the animals at weaning, with the exception of those receiving starch solutions, makes it unlikely. The absence of adequate controls reduces the significance of this study and also of two additional studies, which, at first sight, seemed to clarify the situation. When intraperitoneal injections of a sugar solution were given to suckling rats, the subsequent increase in caries was similar to that caused by oral administration (Steinman, Haley \& O'Day, I958). 'This result suggests a direct systemic action of sugar solutions and eliminates 
possibilities of an indirect effect in the digestive tract and exposure of the newly erupted teeth to concentrated sugar solutions in the mouth. In confirmation of this are the results of a more controlled experiment in which the oral administration of sucrose was restricted to weekly periods during the 2I-day suckling period (Steinman \& Haley, $1957 b$ ). From the analysis of the caries scores in individual teeth it was concluded that the three phases were almost equal in their susceptibility to the influence of the sucrose supplements. This study was incomplete as it did not include a group of animals given sucrose throughout the suckling period, and thus we cannot decide if the effects of sucrose in each of the three periods would be additive. There is at least evidence to suggest that the concentration of sucrose in artificial feeds given to suckling rats is directly related to the subsequent caries scores (Steinman \& Haley, I958). It has been claimed that carbohydrates, acting during tooth development, vary in their ability to alter caries resistance (Steinman \& Haley, 1957 $a, 195^{8}$; O'Day \& Haley, 1959), but the inadequacy of experimental data and the lack of satisfactory control studies and statistical treatment prevent us from grading the different carbohydrates studied by Steinman and his associates.

We ought, however, to return to the question of carbohydrates in the maternal diet in relation to caries susceptibility and in particular the relative importance of two factors, namely the amount and nature of the carbohydrates. Unfortunately, it is only in one or two reports that we find comparisons made of different carbohydrates. Although Sognnaes ( 1948 ) found dextrin to have less pre-eruptive influence on caries than sucrose, Speirs (1963) found wheat starch and sucrose indistinguishable. Usually it is the amounts of carbohydrate that have been studied. Even in the classical study by Sognnaes, it was not just sucrose which was compared with unrefined carbohydrates, but a total of $67 \%$ carbohydrate (as sucrose) compared with $49 \%$ in the stock diet. Studies of this type unavoidably involve alterations in the protein, fat or fibre content and therefore should always be interpreted with this in mind.

Ockerse (1949) found with young rats that the consumption during pregnancy and lactation of an unrefined diet with a high carbohydrate (yellow-maize meal), low protein (crude casein) composition promoted more caries than a similar diet of low carbohydrate, high protein content. It cannot be concluded that these dietary influences were in fact entirely pre-eruptive as the animals were not weaned until 35 days of age, by which time the first and second molars had been exposed to the different diets for about 2 weeks. The replacement during the early part of lactation of a meat diet by one consisting of whole-milk powder and wheat has been reported to cause a marked increase in caries in the offspring (De Grange, Goodlin, Kulka \& Cox, 1957), but obviously many variables, in addition to the carbohydrate content, were introduced in this study. In contrast is the convincing demonstration by Holloway, Shaw $\&$ Sweeney (196r) of the pre-eruptive influence of variations in only the sucrose : casein ratios of purified diets upon tooth morphology and caries susceptibility. The results showed a marked potentiation of caries when the maternal diet contained $83 \%$ sucrose and $8 \%$ casein compared with $67 \%$ sucrose and $24 \%$ casein in the control diet. This effect was entirely pre-eruptive, but was associated with gross 
disturbances in general growth and in tooth morphology, indicative of protein deficiency. However, with $19 \%$ sucrose and $72 \%$ casein in the maternal diet, a marked reduction in caries was noted. Although this effect operated before weaning, part of it may have been mediated during the early posteruptive history of the first and second molars.

It would seem then that animal experiments have established a relationship between carbohydrate consumption during tooth development and caries susceptibility. The possible implications in human nutrition become even more apparent when one considers that the permanent dentition is forming throughout several years of childhood. There is, however, no conclusive evidence from clinical studies to support the experimental results in animals. It is usually impossible to dissociate pre-eruptive from posteruptive influences following a marked change in dietary regimen. Only one study deserves brief mention. In the sudden transition from their primitive to a contemporary 'westernized' diet, the Eskimos have experienced a marked increase in caries (Pedersen, 1938). Refined carbohydrates like sugar, white flour, chocolate and sweets have been introduced, but more relevant to the present discussion is the fact that the total consumption of carbohydrate has risen sixfold and of protein has fallen to one-third (Baarregaard, 1949). From comparisons of the caries incidence in particular age groups, it was suggested that teeth are less cariesresistant when formed on the high-carbohydrate diet.

\section{The influence of carbohydrates on tooth composition}

We must now consider the mechanisms by which carbohydrates might affect caries susceptibility. Our limited knowledge about the carious process, the relationship between tooth composition and caries susceptibility, and the processes of matrix formation and mineralization permit only speculation on the ways by which diet might change tooth composition and so alter resistance to caries. In fact the availability of analytical methods rather than scientific reasoning seems to have often determined the studies undertaken.

Inorganic constituents. Hartles (195 1 ) compared the effects of a purified, highsucrose diet and a stock cube diet on the mineralization of continuously growing rat incisors. The calcium and phosphorus contents of both enamel and dentine were increased in the sugar-fed animals. Although others have failed to observe corresponding alterations in whole molar teeth (Cremer, Büttner, Dittmann \& Voelker, 1953; Haldi, Wynn, Law \& Bentley, I 955), it is misleading to suggest disagreement between these results since it is primarily the influence of the maternal diet and not of the postweaning diet that is being evaluated for the molars.

Luoma (1961) found that there was less deposition of ${ }^{32} \mathrm{P}$ in the molars of weanling rats that had received sugar solutions intraperitoneally during the latter part of the suckling period than in controls given saline. A significant decrease in the $\mathrm{PO}_{4}: \mathrm{CO}_{3}$ ratio, created by decreased phosphate and increased carbonate, was found in the enamel of these molars. In agreement with this is the finding of a $10 \%$ reduction in the phosphate content of developing first molars in suckling rats that had received sugar supplements by mouth since birth (Haley \& Steinman, I957). Both Steinman 
and Luoma attribute the decreased deposition of phosphate to a lowering of serum inorganic phosphate associated with hyperglycaemia. It seems to be well recognized in man and animals that ingestion of refined carbohydrates can lead to a transient decrease in serum inorganic phosphate, and several studies suggest a concomitant rise in the blood calcium level (Page, Ringsdorf, Cheraskin \& Hollis, 196r). My own results confirm these findings. Watson \& Muhler (1959) failed to observe such alterations in the blood of rats receiving a high-sucrose diet, and failed, incidentally, to observe any pre-eruptive influence of this diet. Since lowered $\mathrm{PO}_{4}: \mathrm{CO}_{3}$ ratios in enamel have been associated with increased calcium and reduced phosphate in blood and with increased caries susceptibility (Sobel, Shaw, Hanok \& Nobel, 1960), it is conceivable that the consumption of excess carbohydrate might produce all these conditions. However, even if we accept this suggestion, we do not know if it would extend to the influence of the maternal diet on developing teeth. The findings of Cremer $e t$ al. (1953) and Haldi et al. (1955) make it seem unlikely. Apart from the possibility that maternal hyperglycaemia might raise the foetal blood sugar level (Huggett, I954), we do not know to what extent the effects of a high-carbohydrate diet during foetal or early postnatal life will be affected by systemic influences in the mother, by the placenta and the mammary glands.

Organic constituents. Glycogen and mucopolysaccharides have frequently been demonstrated in developing teeth (Ten Cate, 1962), but there is still uncertainty about their function and little is known concerning their susceptibility to alteration by nutritional influences. Sklans, Dale \& Shklar (1963) found that the partial replacement of wheat flour by sucrose in the maternal diet was without effect on the mucopolysaccharides in developing rat molars. Similar studies involving more drastic alterations of dietary carbohydrate levels would be most interesting. Chemical analyses have confirmed the persistence of carbohydrates in mature enamel (Burgess, Nikiforuk \& Maclaren, I960), and some have suggested that these are influenced by the carbohydrate content of the diet during tooth development (Egyedi, 1953a,b; Buxbaum, Kohn, Proutt \& Oster, 1957; O’Day \& Bavetta, I962).

Egyedi attributed differences in caries incidence between Indonesians and natives of the Netherlands to quantitative differences in the carbohydrate (glycogen and glycoprotein) content of their enamel. Carbohydrate was higher in the more caries-susceptible teeth in the Netherlands. Egyedi not only omits to give the nutritional data necessary to support his contention that the consumption of excess carbohydrate in the Netherlands is responsible for this effect, but he admits that starch is in fact the principal component of the Indonesian diet. The quality rather than the quantity of carbohydrate in the diets must then become the crucial factor. Because of the unequal distribution of carbohydrate within enamel and the possible infiltration of mucin and carbohydrates from oral fluids into early carious lesions (Stack, 1957) the results obtained in all such studies on organic constituents of enamel, particularly those in rat molars, must be interpreted with caution.

Buxbaum et al. (1957) determined the soluble glycoprotein content of hamster teeth and claimed that it was directly related to both the sugar content of the diet during and after tooth development, and the caries scores. The fact that incisors were 
pooled with carious and sound molars for these analyses detracts from the significance of this study. Since the powdered incisors must contribute a large proportion of the sample weight it might well be that the dietary influence is appreciated in only the continuously forming tissues of the incisors. Stack \& Holloway (I959) studied the total carbohydrate content of molar enamel and dentine in young rats reared on two diets with contrasting sucrose : casein ratios. They concluded that retarded growth was responsible for the apparent increase in carbohydrate in the teeth of animals on the high-sucrose, low-casein diet, since this difference was eliminated when rats of equal growth status were compared. A marked reduction in the carbohydrate content occurred with age. A similar age effect has been reported for the hexosamine content of whole molars (O'Day \& Bavetta, I962). Weanling rats from mothers receiving a purified, high-sucrose diet during lactation contained significantly less hexosamine and possibly more collagen in their molars than controls raised on a stock diet. These differences became progressively reduced over a period of 3 weeks. These results cannot be reconciled with the increased nitrogen contents found in the molars of mature rats on high-sucrose diets (Haldi et al. 1955). O'Day \& Bavetta (1962) suggest that 'alteration of the organic matrix would influence mineralization' and hence might influence caries susceptibility. Even if this hypothesis is accepted, it is probable, in view of the fact that whole teeth were analysed in this study, that this 'alteration' occurred primarily in the dentine.

\section{Other systemic mechanisms by which carbohydrates might influence caries}

Alloxan diabetes increases caries incidence in mature rats given a cariogenic diet (Hartles \& Lawton, 1958; Sweeney, Shaw \& Rubin, 1962), and intraperitoneal injections of sugar solutions have a similar effect (Steinman \& Hardinge, I958). These observations would support the claim made by Steinman (1962) that 'resistance to decay is metabolic as well as structural.' The composition of saliva might be regarded as one of the 'metabolic' factors. Unfortunately, we cannot, with much confidence, relate the variations in the composition of saliva, which have been ascribed to the ingestion of excess carbohydrate, to variations in caries susceptibility. It might seem unnecessary to emphasize that 'oral fluid' is not synonymous with 'saliva', but failure to make this distinction causes confusion, particularly in papers concerned with 'salivary' glucose levels.

Only a small amount of free glucose is present in saliva and it is almost independent of the blood glucose level over the physiological range. 'The significance of the glucose content is probably minimal when compared with the local concentrations of carbohydrate in the mouth after eating.

There is disagreement concerning the possible adaptation of salivary amylase to dietary carbohydrate levels and also the relation between amyloly tic activity and caries. From the data collected by Turner (1960) it seems that some of the apparent controversy can be attributed to variations in experimental methods. One also wonders if the recent finding that sucrose in the mouth can promote increased amylase content in parotid saliva (Newbrun, I963), might not have contributed to the results of certain studies showing amylase adaptation to diet. 
Probably of more importance is the transient reduction in salivary phosphate which follows the consumption of excess glucose (Eddy, Heft, Rosenstock \& Ralston, I933), and the reduction of the buffering capacity of saliva both after meals rich in carbohydrate or sugar and during prolonged periods of imposed high carbohydrate intake (Wills \& Forbes, 1939; Ericsson, 1959). These effects might reflect a fall in serum inorganic phosphate or may be due to an alteration in the metabolism of the salivary glands. That variations in the composition of the diet can alter the histological appearance of the glands has been reported (Ershoff, Brann \& Bavetta, I962). It has also been shown that increased dietary sucrose promotes increased salivary viscosity (Elzay \& Muhler, I 958), but an attempt to relate the viscosity, flow rate and caries incidence to the carbohydrate component of the diet was unsuccessful (Elzay \& Muhler, 1962). Further studies of this type would be of interest, since the viscosity and rate of flow of saliva are undoubtedly concerned in the aetiology of dental caries.

Although we have seen that the composition of teeth and saliva is influenced by carbohydrate consumption, there is still insufficient proof that these alterations are responsible for variations in caries susceptibility.

\section{REFERENCES}

Baarregaard, A. (I949). Oral Surg. 2, 995.

Burgess, R. C., Nikiforuk, G. \& Maclaren, C. (1960). Arch. oral Biol. 3, 8.

Buxbaum, J. D., Kohn, H., Proutt, L. M. \& Oster, R. H. (1957). F. dent. Res. 36, 173.

Cremer, H. D., Büttner, W., Dittmann, G. \& Voelker, W. (1953). Biochem. Z. 324, 83.

De Grange, D. W., Goodlin, S. D., Kulka, N. \& Cox, G. J. (1957). Proc. 35th General Mtg int. Ass. dent. Res., Atlantic City, Abstract no. 167.

Eddy, W. H., Heft, H. L., Rosenstock, S. \& Ralston, R. (1933). F. dent. Res. 13, 5 I I.

Egyedi, H. (1953a). Dent. Items, 75, I 13 .

Egyedi, H. (1953 $b)$. Dent. Items, 75, 971 .

Elzay, R. P. \& Muhler, J. C. (I958). F. dent. Res. 37, 53 (Abstract).

Elzay, R. P. \& Muhler, J. C. (1962). Dent. Progr. 2, I 99.

Ericsson, Y. (1959). Acta odont. scand. 17, I3I.

Ershoff, B. H., Brann, A. S. \& Bavetta, L. A. (1962). F. dent. Res. 41, 853.

Haldi, J. \& Wynn, W. (1952). F. Nutr. 46, 425 .

Haldi, J., Wynn, W., Law, M. L. \& Bentley, K. D. (1955). F. Nutr. 57, 215.

Haley, M. I. \& Steinman, R. R. (1957). Proc. 35th General Mtg int. Ass. dent. Res., Atlantic City, Abstract. no. 182 .

Hartles, R. L. (I95 I). Biochem. F. 48, 245.

Hartles, R. L. \& Lawton, F. E. (1958). Brit. J. Nutr. 12, 286.

Holloway, P. J., Shaw, J. H. \& Sweeney, E. A. (1961). Arch. oral Biol. 3, 185.

Huggett, A. St. G. (1 954). Cold Spr. Harb. Symp. quant. Biol. 19, 82.

Luoma, H. (1961). Arch. oral Biol. 3, 27 I.

McClure, F. J. (195I). F. Nutr. 43, 303.

Mitchell, D. F. \& Shafer, W. G. (I949). F. dent. Res. 28, 424,

Newbrun, E. (1963). F. dent. Res. 41, 459.

Ockerse, T. (1949). Dental Caries, Clinical and Experimental Investigations. Pretoria: Department of Health.

O'Day, P. \& Bavetta, L. A. (I962). F. Nutr. 78, 37.

O'Day, P. \& Haley, M. I. (1959). F. dent. Res. 38, 685 (Abstract).

Page, M. E., Ringsdorf, W. M., Cheraskin, E. \& Hollis, C. F. (I961). Tex. dent. F. 79, 7.

Pedersen, P. O. (1938). Dent. Rec. 58, I9I.

Shaw, J. H. \& Griffiths, D. (1963). Y. dent. Res. 42, I 198.

Shaw, J. H., Schweigert, B. S., McIntire, J. M., Elvehjem, C. A. \& Phillips, P. H. (1944). F. Nutr. 28, 333 .

Shaw, J. H. \& Sognnaes, R. F. (1955). In Advances in Experimental Caries Research, p. 82. [R. F. Sognnaes, editor.] Washington: American Association for the Advancement of Science.

Sklans, S., Dale, P. \& Shklar, G. (1963). F. dent. Res. 42, 889. 
Sobel, A. E., Shaw, J. H., Hanok, A. \& Nobel, S. (1960). F. dent. Res. 39, 462.

Sognnaes. R. F. (1948). J. Amer. dent. Ass. 37, 676 .

Sognnaes, R. F. \& Shaw, J. H. (1954). F. Nutr. 53, 195.

Speirs, R. L. (1963). F. dent. Res. 42, 1 103 (Abstract).

Stack, M. V. (1957). 7. dent. Res. 36, 325 .

Stack, M. V. \& Holloway, P. J. (1959). F. dent. Res. 38, 1223 (Abstract).

Steinman, R. R. (1962). Dentist, I, no. I.

Steinman, R. R. \& Haley, M. I. (1957a). F. dent. Res. 36, 532.

Steinman, R. R. \& Haley, M. I. (1957b). Proc. Soc. exp. Biol., N.Y., 94, 39 I.

Steinman, R. R. \& Haley, M. I. (1958), F. Dent. Child. 24, 211.

Steinman, R. R., Haley, M. I. \& O'Day, P. (1958). F. dent. Res. 37, 7 I9.

Steinman, R. R. \& Hardinge, M. G. (I958). $\mathscr{~}$. dent. Res. 37, 874 .

Sweeney, E. A., Shaw, J. H. \& Rubin, R. P. (r962). F. dent. Res. 4r, 866.

Ten Cate, A. R. (1962). Arch. oral Biol. 7, r.

Turner, N. C. (1960). F. Amer. dent. Ass. 61, 20.

Watson, B. D. \& Muhler, J. C. (1959). F. dent. Res. 38, 618.

Wills, J. H. \& Forbes, J. C. (1939). F. dent. Res. 18, 409.

\section{Changes in the pattern of carbohydrate consumption in Britain}

By J. P. Greaves and Dorothy F. Hollingsworth, Ministry of Agriculture, Fisheries and Food, Great Westminster House, Horseferry Road, London, SWI

Interest in carbohydrates, for long neglected by nutritionists, is reviving; this paper attempts to provide a factual assessment of carbohydrate consumption in Britain, as it exists today, and as it has changed over the past quarter-century. Estimates of consumption going back farther are necessarily less reliable, but general observations may be made with confidence. Thus it is well known that bread in former times occupied a much more prominent position in the diet than it does today: Lloyd (1936) has estimated that at the end of the eighteenth and early in the nineteenth century this one item represented $50 \%$ of the weekly expenditure on food in the labouring classes; today the proportion is about $7 \%$.

\section{Carbohydrate in the modern diet}

National Food Survey (NFS) records for 1961 (Ministry of Agriculture, Fisheries and Food, unpublished information) showed that for all the households surveyed, bread and flour provided on average just over a third of the total carbohydrate and potatoes $10 \%$, sugar and preserves together about a quarter, and milk 6\% (Table 1 ). These three groups respectively provide carbohydrate predominantly as starch, sucrose and lactose.

It must be remembered, however, that the NFS does not record consumption of chocolates, sweets, ice-cream (other than that consumed at meals) or soft drinks: expenditure on these items in 1962 averaged $6.5 \%$ of total household expenditure on food, excluding that spent on meals out (Ministry of Labour, 1963). Furthermore, the term consumption, as used in the Survey and in this paper, must not be confused with ingestion: it refers to the quantity of food entering the household which is available for human consumption, and though the nutrient conversion factors make allowance for the presence of inedible material such as potato peelings, losses of 